\title{
A BUSCA DA COMPREENSÃO DO HUMANO E SEU MUNDO
}

\section{THE SEARCH OF COMPREHENSION OF THE HUMAN BEING AND YOUR WORLD}

lael de Souza ${ }^{1}$

\section{RESUMO}

Esse artigo tem como finalidade contribuir para a reflexão da função social desempenhada pela magia, pelo mito e pela religião na construção da compreensão do mundo pelos homens, de uma perspectiva ontológica e materialista, analisando como esses diferentes momentos da constituição do pensamento e consciência humanos se interpenetram, e no desenvolvimento processual da evolução do ser pré-humano para o ser social, acabam agindo simultaneamente para a construção das representações de mundo, orientando e justificando as práticas socioculturais das formações sociais em constante complexização.

Palavras-chave: Magia - Mito - Religião - Consciência.

\begin{abstract}
This article aims to contribute to the reflection on the social function performed by magic, myth and religion in building men comprehension of the world, through an ontological and materialistic perspective, by analyzing how these different moments in thought process and conscience of man merge, and the procedural development of evolution from prehuman being to social being, end up simultaneously moving toward the building process of world representations, assisting and justifying sociocultural practices of social formations in a constant cumbersome process.
\end{abstract}

Keywords: Magic. Myth. Religion. Conscience.

\section{INTRODUÇÃO}

Os seres humanos necessitam justificar e significar o modo como vivem, atribuindo sentido para suas vidas. Essa necessidade aparece quando do salto qualitativo gerado pela tomada de consciência dos homens de sua humanidade e diferenciação dos demais seres e da natureza, como demonstra Lessa (1996), criando o mundo sociocultural, as sociabilidades humanas.

O aparecimento da consciência resulta de um longo processo de mudanças substantivas relativas às formas de respostas dadas pelos hominídeos as 
suas necessidades básicas e imediatas de manutenção e reprodução material, que satisfeitas, criam as condições para o surgimento de novas necessidades, para além das naturais, exigindo uma maior manipulação do mundo.

Nesse sentido, a reflexão e análise aqui realizadas, de uma perspectiva ontológica e materialista, demonstra que a magia, o mito e a religião desempenham uma função social fundamental no processo do desenvolvimento do pensamento consciente racional, permitindo uma manipulação mais eficiente do real e a criação dos referenciais proto-éticos que justificam e embasam as ações sociais nas sociabilidades humanas.

Este artigo contribui com as reflexões e análises desenvolvidas na área das humanidades, visando uma compreensão cada vez mais totalizadora do fazerse homem dos homens, que por terem como característica constitutiva essencial o inacabamento, estão sempre buscando resignificar a compreensão de sua historicidade, explorando outras dimensões e perspectivas, aperfeiçoando e aprofundando o conhecimento de si e do mundo no esforço de ser mais e melhor.

\section{MAGIA, MITO, RELIGIÃO E O PENSAMENTO RACIONAL}

As primeiras formações humanas defrontam-se com a questão da sobrevivência no mundo. A existência, sua manutenção e a reprodução das condições de vida são questões primordiais - ainda que a reprodução, num primeiro momento, seja um encargo da natureza, pois os bandos de hominídeos esperam pela sua providência, já que não sabem produzir o próprio alimento. Portanto, o problema central está em buscar conhecer e explicar o mundo para poder sobreviver a ele e nele, embora, num primeiro momento, essa "explicação" não tenha um caráter racional, lógico, como entendemos hoje e segundo a tradição aristotélica.

A primeira forma de conhecimento é a prática-imediata, utilitária, onde os órgãos dos sentidos ${ }^{2}$ são e funcionam como os tradutores e organizadores do aparente caos fenomênico que é o mundo. Não há pensamento, mas experiência, reflexos mecânicos feitos através do ensaio e erro ${ }^{3}$.

Eis a essência do reflexo mental: é mecânico, não há ainda consciência. Essas ações reativas são respostas às necessidades imediatas que procuram atender imitando o que observam na natureza, forma encontrada para sobreviver, se 
defender e se afirmar perante os demais animais que concorrem pelo espaço e pelos recursos naturais, quase sempre escassos.

A magia é a primeira forma de organizar o mundo, tornando-o operacionalizável, manipulável. O imediato é que dita as ações, as práticas e as representações do imaginário dos hominídeos, mais tarde organizados em comunidades. Nada é sistematizado, compreendido e formulado conceitualmente. São o costume, o hábito e as "tradições" que regem a dinâmica da vida "comunal", continuados e passados gestualmente, oralmente entre os bandos tornados, em sua evolução, gerações.

A tentativa empreendida pelos hominídeos de imitar e reproduzir a ininteligível força mágica do mundo natural tem como base a própria matéria, a sua legalidade imanente ainda não conscientemente compreendida, decifrada e manipulada, mas intuída. Magia e sentimento têm, nessa fase, certa homologicidade, dado que a primeira não se explica, mas é um desdobramento potencializado e hiperdimensionalizado dos sentidos. É o momento da explosão do natural e da força da natureza existente no interior do metabolismo dos hominídeos e virtuais seres sociais, força que se exterioriza e materializa numa descarga e troca de energias contidas em todas as matérias. ${ }^{4}$

O hominídeo não atribui características humanas - processo de antropomorfização - a esses elementos e fenômenos porque ele mesmo ainda não tomou consciência de sua humanidade e da sua potência de realizar o salto qualitativo que o funda como ser social.

Através da visão de mundo mágica os hominídeos crêem que sua força e coragem ampliam-se mediante a posse de determinados objetos naturais então minimamente aperfeiçoados por eles com o fim de prestar maior eficiência à atividade que se entrega e pela qual é absorvido ${ }^{5}$.

A mente é como um espelho que reflete o que vê e procura organizar esses dados conforme as necessidades imediatas sentidas e vividas. A natureza é o corpo inorgânico da comunidade, sua extensão, que garante as condições objetivas para reprodução da vida material.

Os homens estão subsumidos e submissos às forças naturais, a elas prestam culto em seus cerimoniais de fertilidade, trabalho e outros. Não se difere o bem do mal, que encontram-se entrelaçados; não há, portanto, noções proto-éticas. 
A magia põe o homem e a natureza em relação direta, sem a mediação de um DEUS, um demiurgo, como ocorre na religião, gerando um saber imperfeito e não verificado do mundo. Daí dizermos que possa ser compreendida enquanto uma forma de proto-pensamento, um mecanismo de funcionamento mágico que produz um reflexo mecânico, de respostas a necessidades imediatas que encontram sua satisfação na forma de funcionamento da natureza, nas forças naturais, que adquirem a força de condicionar os movimento dos hominídeos e ditar a forma de garantirem sua sobrevivência e convivência, inicialmente instintiva.

O "pensamento" mágico é uma forma específica de proto-pensamento onde não encontramos a lógica, a sistematização, portanto, um não-pensamento; entretanto, estabelece uma forma peculiar de mediação que permite a construção de uma determinada representação de mundo, essencialmente intuitiva, sensitiva.

Daí aproximarmos esse proto-pensamento de uma outra fase, mais aperfeiçoada e relativamente superior, que seria o pensamento mítico, que traz a marca da antropomorfização, produto da mutação qualitativa do hominídeo em ser social (ANDERY, et. al.: 1996), que se distancia e diferencia da natureza e do natural, embora esse distanciamento e diferenciação estejam, inversamente, determinados pelo elo inquebrantável existente entre homem e natureza (ENGELS: 1979).

Porém, no universo mítico ainda há a remanescência da força do desconhecido, do inexplicável, do mágico, que é o acaso - que não deve ser tratado como sinônimo de coincidência -, atuando vez por outra em situações que não apontam saída, nem escapatória. Os mitos gregos são exemplares nesse sentido.

O mito seria, assim, uma fase intermediária para a passagem a um outro estágio do desenvolvimento das formações-socioculturais onde desenvolve-se o pensamento religioso. Segundo Lukács, uma ontologia fictícia que em determinados momentos e períodos da processualidade histórica, produtiva, social joga um papel vital e essencial para plenificar a vida humana de sentido, significando-a.

(...) com o desenvolvimento da sociabilidade, a materialidade social, as relações sociais que articulam os homens entre si e com a natureza assumem uma objetividade própria - com o que, na cotidianidade, elas se relacionam com os atos singulares, com a teleologia de cada indivíduo em cada momento, com a mesma 'dureza' que as relações causais dadas, naturais. (...)

Nessa situação, a vida do indivíduo recebe determinações que, na imediaticidade, Ihe parecem absolutamente externas - e que do ponto de vista de sua individualidade lhe parecem absolutamente arbitrárias. Que, no 
bojo de uma crise econômica, uma parte dos capitalistas irão à falência, e uma parte dos trabalhadores terão seus filhos mortos pelo desemprego e pela fome é algo fácil de ser compreendido (mas, certamente, não de ser aceito). Todavia, que seja o João ou o Antônio quem sofrerá estas consequências negativas da crise - ainda que aqui o comportamento concreto dos indivíduos possua alguma importância - é algo que possui muito de acaso. A confrontação com este acaso - por que eu? Por que comigo? - desperta a necessidade de uma vida 'plena de sentido'.

Este é o solo pelo qual, através de inúmeras mediações que correspondem à peculiaridade de cada momento histórico, nasce a idéia de um destino, e de uma consciência toda poderosa que conduz esse destino, conferindo um sentido superior, pleno, àquilo que parece carecer de sentido na vida cotidiana. A espontânea teleologia da vida cotidiana, neste sentido, contribui a edificar sistemas ontológicos nos quais uma vida individual sensata aparece como parte, como momento de uma obra teleológica de salvação do mundo. (...) Importante é que a vontade de conservar uma sensata integridade da personalidade - que a partir de um determinado estágio é um problema notável da vida social - encontra uma base de apoio espiritual em uma ontologia fictícia [a religião, o pensamento religioso, por exemplo] nascida a partir de tais necessidades.

(...) Uma interpretação falseada, uma ontologia fictícia, pode jogar um papel fundamental no desenvolvimento do gênero humano. Normalmente, tal ontologia fornece uma compreensão provisória do cosmos que situa 0 homem em uma determinada relação com o existente, influenciando o desenvolvimento de sua visão de mundo e, deste modo, também influenciando, mais ou menos diretamente, a própria reprodução do social.

(...) A religião pode ser uma forma de tomada de consciência, em escala social, de necessidades e dilemas reais que a humanidade enfrenta no seu desenvolvimento e, por isso e nesta medida, jogou em vários momentos um papel importante no devir humano dos homens. A figura do herói clássico, ou a condenação ou salvação no paraíso, ao concederem um sentido transcendente à vida terrena, foram mediações importantes através das quais os indivíduos puderam referir a si próprios as demandas e as exigências postas pelo desenvolvimento do gênero humano enquanto tal. (LESSA, 1996a, p. 40-42. Grifo nosso.)

Enquanto ontologia fictícia, não importa se as máximas e axiomas religiosos são verdadeiros ou não, o que verdadeiramente pesa é se elas adquirem função social, passando a guiar e orientar a ação dos indivíduos sociais, ou melhor, de determinados grupos sociais, influenciando-os nas escolhas entre alternativas que realizam diariamente, fazendo com que ajam, pensem, sejam, percebam a si mesmos e ao mundo de uma determinada maneira e não de outra.

A religião é, pois, um produto da complexidade e complexização da vida societal, da imposição de novas necessidades que ultrapassam a operacionalidade da natureza, quebrando a subsunção e submissão do homem em relação ao natural, proporcionando ações que refletem mais o social, a organização complexa e dinamizada da sociabilidade do que a organização segundo uma lógica natural.

Os homens passam a se enxergar e compreender enquanto seres distintos da natureza. Constroem novas normas e modos de comportamento, e os 
legitimam, justificam e representam através da criação de uma ética, posta, num primeiro momento, pelo pensamento religioso, onde o conhecimento do mundo e dos seus fenômenos é revelado e pode ser compartilhado por intermédio da fé 6 .

Não é mais a imediaticidade que regula e rege a dinâmica da vida humana, mas sim reflexões mediativas, embora sejam concepções antropomorfizadas e antropomorfizadoras do mundo, ou seja, os "poderes humanos são potencializados e absolutizados em poderes divinos; o acaso e o desconhecido são explicados pela vontade - esta muitas vezes inexplicável - dos deuses". (LESSA, 1996b)

Conforme diz Mazzeo:

\begin{abstract}
[A religião desempenha, num dado estágio do desenvolvimento do ser social,] o papel organizativo no processo de construção de formas mediativas na relação do homem com 0 mundo material $e$, consequentemente, na estruturação de superiores qualidades ideoreflexivas da realidade objetiva na consciência cotidiana. Portanto, a complexização societal, resultante do alargamento das respostas às necessidades engendradas pelo processo mesmo de objetivação das formas de sociabilidade, propiciam não somente a ampliação do conhecimento prático-imediato, que se desenvolve no sentido da sofisticação técnica, como requer também - e, enquanto elemento da essencialidade -, a construção de mediações que estejam atendendo aos novos problemas postos pela dinâmica histórico-concreta das formas da divisão do trabalho e por relações sociais diferenciadas que se constroem a partir do surgimento da propriedade privada e de uma hierarquização societal - a divisão da sociedade em classes ou estamentos. (MAZZEO, 2003a, n. p. Grifo nosso.)
\end{abstract}

Enquanto no mundo mágico a comunidade está diretamente conectada à natureza, mesmo porque vincula-se corporiamente a ela, nas sociedades religiosas, como resultado de um grande e longo processo histórico de ações teleológicas, finalísticas, previamente ideadas, que denotam um grau de complexização societal muito mais denso, a comunidade reordena ou mesmo dissolve os laços de complementaridade com a natureza. A religião engendra novas formas mediativas, novas práxis sociais, ultrapassando os meros reflexos imediatizados da natureza, transformando-se, progressivamente, em reflexos da sociedade. Novamente, segundo Mazzeo:

A convivência e a colaboração dos homens deixa de ser uma óbvia naturalidade regulada por uma tradição de eficácia cotidiana, como o costume. (...) Essa convivência e essa colaboração tornam-se problemáticas, e para a resolução de questões, para a conservação e para a reprodução de uma sociedade que atinge complexas gradualidades de contradições, os homens se vêem obrigados a elaborar novas objetivações, 
novos modos de comportamento - para substituir os velhos em processo de consumpção - sendo que um deles é a ética.

(...) Os pressupostos histórico-ontológicos para a construção de uma ética estão dados pela forma religiosa e pela elaboração de uma cosmogonia provedora de satisfações de necessidades que permitem a superação de uma existência imediatizada dos homens. De modo que a ontologia religiosa que surge de maneira oposta àquela científica, contraditoriamente, oferece os fundamentos para um processual distanciamento da imediaticidade, mesmo que através de concepções antropomórficas do mundo.

A estrutura religiosa tem como fundamento radical de sua existência a idéia de salvação do homem. (...) A criatura (fenômeno) e a essência (deus) referem-se diretamente ao sujeito em busca de salvação. (...) $O$ comportamento religioso proporciona o destacamento da cotidianidade comum, através de uma enfática acentuação da fé. (...) O conhecimento dado apresenta-se a partir de uma 'revelação superior', onde o empírico surge, também ele, como um elemento componente da revelação, quer dizer, a manifestação fenomênica não se distingue dos fatos comuns a não ser pela ênfase posta pela fé. Daí a possibilidade de se buscar uma harmonização entre religião e conhecimento, isto é, a unificabilidade do empírico e da revelação.

As sociedades que alcançaram formas mediativo-religiosas de representação, em geral, desenvolveram conhecimentos fundamentais que contribuíram para o desenvolvimento de respostas às necessidades essenciais àquela dinâmica social, vivenciando um notável processo de desenvolvimento de forças produtivas, que implicou, inclusive, em grandes conhecimentos científicos e no aperfeiçoamento de técnicas sofisticadas, como o controle de fluxos dos rios (através de sistemas de comportas), de construção de estradas, de templos e de palácios.

[Entretanto], a ausência de um tipo de pensamento que possibilite desvincular o trabalho da práxis utilitária [é a principal limitação]. Ainda que se produzam inovações científicas e técnicas, a falta de 'circulação' de idéias, determinadas por um sistema extremamente fechado, impede o desenvolvimento de formas mediativo-críticas que apontem para a generalização do conhecimento e para a construção de um pensamento filosófico-especulativo, que possa contrapor-se às concepções antropomorfizadoras do mundo. (MAZZEO, 2003b, n. p. Grifo nosso.)

Logo, o pensamento religioso é uma forma de consciência. A explicação religiosa permite a separação entre homem e natureza através da criação da figura de um demiurgo antropomorfizado, possibilitando aos homens uma margem maior de ação sobre o mundo, ainda que limitada, já que o homem é apenas criatura, imperfeita e pecadora.

A particularidade da religião, enquanto sistematização institucionalizada do saber - portanto, um saber oficializado e reproduzido continuamente por suas instituições sociais correspondentes, que o difunde nas sociedades humanas, legitimando as crenças ${ }^{7}$ que justificam a forma de viver dos homens, orientando sua forma de ser, introduzindo uma ética em relação à explicação mítica ${ }^{8}$ - só existe para a cultura do mundo ocidental, e muito dela está impregnada e foi internalizada por nós, dificultando exercitar o nosso olhar para o reconhecimento do outro, da 
alteridade, da única semelhança que existe entre os homens, da sua unidade, que é o fato de serem diferentes, plurais, polifônicos, assimétricos, o que lhes permite e possibilita um enriquecimento inimaginável através das trocas das práticas socioculturais, tornando-os, cada vez mais, gênero humano, interdependentes e interdeterminantes. (LAPLANTINE: 2005)

Como pudemos notar, magia-mito-religião, apesar de serem momentos distintos da origem do pensamento humano, se interpenetram, se imiscuem, e no desenvolvimento processual da evolução do ser pré-humano para o ser social, acabam agindo simultaneamente para a construção das representações de mundo que orientarão e justificarão as práticas socioculturais das formações sociais em complexização constante.

O que efetivamente difere os homens dos animais não é o fato dos primeiros serem dotados de razão, na verdade, o salto qualitativo que proporciona o nascimento do ser social é a consciência, esta sim capaz de fazer com que esse "ser" se diferencie dos demais animais e da própria natureza, - rompendo-se, assim, o elo mágico - colocando como momento predominante a produção do novo como condição para a reprodução do próprio ser social, de uma segunda natureza, que é a sociabilidade humana, estruturada e organizada segundo necessidades que vão além do intercâmbio entre homem e natureza, que ultrapassam a mera reprodução das condições físico-biológicas, essencialmente ligadas ao mundo inorgânico, à natureza e toda sua magia.

O elo entre homem e natureza é, indubitavelmente, inquebrantável, porém, o ser social, ao dar novas formas e finalidades aos objetos naturais os torna objetos sociais, ainda que suas propriedades naturais permaneçam enquanto parte da legalidade imanente que possibilita a criação e produção de tais objetos para servir aos fins humanos.

O trabalho é a protoforma, isto é, a forma originária do ser social, é o que o funda enquanto homem, o que o humaniza e diferencia, atribuindo-Ihe uma identidade singular, específica. Porém, o trabalho funda o ser social, mas o ser social não se resume, nem se esgota, ao e no trabalho. O processo de complexifização da vida e das condições objetivas e objetivadas (criadas pelos homens através de suas atividades, atividades essas que se ampliam, renovam e também se tornam cada vez mais complexas e interdependentes, dependendo cada 
vez mais do processo de generalização humana e das intermediações entre os homens de diferentes espacialidades e temporalidades), exigirão a criação de outros complexos, além do trabalho, como a ética, a ideologia, a moral, o direito, a linguagem, a cultura, etc..

Esses demais complexos adquirem uma autonomia relativa em relação ao complexo dos complexos, que é o trabalho. Eles são fruto do desenvolvimento das práticas socioculturais, respostas a situações, circunstâncias, momentos onde o pensamento científico não é capaz de encontrar as respostas e, novamente, entra em cena o pensamento religioso-mítico ou mesmo mágico, onde não raro o acaso e o acidental desempenham relevante função de justificar e plenificar de sentido a vida humana e todos os fenômenos existenciais e experimentais que a cercam.

De modo que devemos tomar cuidado para não separarmos essas formas de mediação intuitivas, primárias, secundárias e superiores, tentando delimitar suas durações espaço-temporais, pois é necessário estarmos cientes de que dependendo das circunstâncias históricas-sociais objetivas, do nível e estágio do desenvolvimento do ser social, essas formas mediáticas poderão ressurgir e cumprir uma importante função social para o avanço progressivo do gênero humano, como bem expôs Lessa através de Lukács.

As variações das ordenações, representações, explicações, concepções e categorias do entendimento e pensamento humanos cumprem a função social de adequar e garantir a adaptação e sobrevivência da cultura de determinada formação social, possibilitando uma transição mais tranquila e menos caótica a níveis de complexização da vida societal exigidos pelas novas necessidades criadas pelos indivíduos sociais quando da satisfação das antigas necessidades, elevando para um patamar superior as forças produtivas e o conhecimento técnico-científico. Ainda assim, há situações e momentos onde a ciência não é capaz de encontrar as respostas e, novamente, entra em cena o pensamento religioso-mítico ou mesmo mágico, como já explicitamos.

Sendo assim, também podemos entender a religião de modo subjetivo, enquanto atitude através da qual a criatura humana se orienta para o Outro divino, e objetivamente, como o conjunto de noções, normas, ritos, rituais, crenças pelos quais nos ligamos a esse Outro.

Apesar dos avanços do pensamento humano e do desenvolvimento produtivo, 
histórico-social do ser biopsicosociocultural, da complexização das necessidades naturais pela criação e reposição constante e ampliada das necessidades sociais no tempo e espaço, fazendo avançar as forças produtivas e a interdependência dos homens, tornando-os, indubitavelmente, cada vez mais gênero humano, devido ao crescimento da interdependência ontosociocultural, ainda assim, a máxima grega do "corpo são, mente sã" ecoa como alerta e apontamento para a complexa natureza humana.

Materialidade e imaterialidade são partes dialéticas da totalidade do ser humano, social. Corpo, a matéria; mente, o imaterial; ambos conectados, interdeterminados e, concomitantemente, distintos. Enquanto o primeiro tem sua funcionalidade e operacionalidade exploradas e tornadas, cada vez mais, cognoscíveis, permitindo as intervenções humanas, a segunda tem um lado meio obscuro, quase incognoscível, mas que instiga os estudiosos, pesquisadores e cientistas, que o sondam e perseveram em desvelar.

Dentro dessa perspectiva, podemos asseverar que o mágico e divino está em nós, fazendo parte da própria cosmogonia do universo. Essa divindade inerente ao ser social parece se manifestar quando dos momentos de superação de dificuldades e situações que pareciam ser insolúveis e impossíveis de se resolver. 0 divino, a divindade são então sentidos como sendo parte constitutiva do ser humano, por mais que ele tente negar, suprimir ou suspender, mesmo os ateus.

Jung, renomado psicanalista, discípulo de Freud, em certa altura de sua vida e execução profissional, relata e testemunha:

\footnotetext{
Entre todos os meus pacientes de mais de 35 anos, não há um sequer para quem o problema fundamental não seja a atitude religiosa. Em última análise, todos se tornaram doentes porque haviam perdido a força da crença religiosa. Nenhum sarou enquanto não se reencontrou religiosamente. (Pierre Dentin apud VANNCCHI, 1979, p. 35)
}

Concluindo, ontologia fictícia ou não, cabe aqui ponderarmos sobre a natureza do ser humano, um ser natural e social, uma matéria que carrega em si as forças (nem sempre "cientificamente" conhecidas, embora psicologicamente explicadas) e lógica da reprodução natural; sentida, experimentada, vivenciada ao longo da sua existência, ora racional, ora sensorialmente, em termos afetivosemocionais, demonstrando o quanto a assertiva "conhece a ti mesmo" é sintomática 
e explicita a necessidade de buscarmos compreender o ser humano enquanto parte de um complexo maior que é o metabolismo universal. ${ }^{9}$

\section{REFERÊNCIAS}

ANDERY, Maria Amália Pie Abib... et al. Para Compreender a ciência: uma perspectiva histórica. 6 ed. rev. e ampl. Rio de janeiro: Espaço e Tempo: São Paulo: EDUC, 1996.

CAPRA, Fritjof. Trad. Álvaro Cabral. O Ponto de Mutação - A Ciência, a Sociedade e a Cultura emergente. São Paulo: Cultrix, 1982.

ENGELS, Friedrich. A Dialética da Natureza. 3 ed. Rio de Janeiro: Paz e Terra, 1979.

FISCHER, Ernst. A necessidade da Arte. 4 ed. Trad. Leandro Konder. Rio de Janeiro: Zahar, 1973.

JAEGER, Werner. PAIDÉIA - A formação do homem grego. Trad. Artur M. Parreira. São Paulo: Martins Fontes, 1995.

LAPLANTINE, François. Aprender Antropologia. Trad. Marie-Agnês Chauvel. São Paulo: Brasiliense, 2005.

LESSA, Sérgio. Ontologia de Lukács. Maceió: EDUFAL, 1996. (Didática-EDUFAL; 2).

MAZZEO, Antonio Carlos. Determinações Histórico-ontológicas da construção das formas político-mediativas no Ocidente Antigo. (Parte I - Mediação, Magia e Religião no Mundo Antigo: Elementos Teórico-Analíticos para uma Análise Aproximativa). Tese de livre docência, 2003, não paginado.

VANNUCCHI, Aldo. Filosofia e Ciências Humanas. São Paulo: Edições Loyola, 1979. 
${ }^{1}$ E-mail: iaeldeo@gmail.com. Mestre em Ciências Sociais. Professora Assistente da Universidade Federal do Piauí. Departamento de Educação.

${ }^{2}$ Conforme Fischer, "a mão é o órgão essencial da cultura, o iniciador da humanização. Isso não quer dizer que tenha sido a mão sozinha que fez o homem; a natureza (particularmente a natureza orgânica) não admite semelhantes simplificações, semelhantes sequências unilaterais de causa e efeito. (...) Já São Tomás de Aquino estava ciente dessa significação única da mão, esse órgão dos órgãos e expressou-o na sua definição do homem: $O$ homem possui razão e mão. E é verdade que foi a mão que libertou a razão humana e produziu a consciência própria do homem". (FISCHER: 1973, p. 22 e 23) Uma pena que a mão tenha evoluído mais rápido que o cérebro, que parece não acompanhar suas proezas, como já concluíra Monteiro Lobato, em A História das Invenções.

${ }^{3}$ De fato, o processo de humanização e constituição do ser social foi progressivo, lento, gradual, cheio de avanços e recuos, e antes do pensamento consciente propriamente dito, houve uma fase demorada de experimentações, de ensaios e erros, de tentativas nem sempre bem sucedidas, mas geralmente frustradas, que proporcionaram as condições para as associações, as memorizações, que são, num primeiro momento, reflexos mecânicos, condicionados, e não conscientes, propositados. Eis aí o nó górdio da questão.

${ }^{4}$ A física quântica explica que é possível, conhecendo e sabendo manipular essa "força natural interior", materializar o pensamento. Por exemplo: imaginar um relógio e torná-lo concreto. Algumas dessas possibilidades são ilustradas através do documentário Quem somos nós? Outras ponderações a respeito podem ser realizadas mediante a leitura da obra de Capra (1982).

${ }^{5}$ A eficiência antecede o propósito, a atividade teleológica. É interessante ressaltarmos que mesmo no mundo contemporâneo certos rituais mantidos por determinadas formações sociais remetem à força mágica, como a crença de que ingerir um coração de um oponente de igual ou maior coragem que a si mesmo pode contribuir para aumentar a bravura e destemor de quem dele se serve. O filme Coração Valente ilustra bem essa prática sociocultural.

${ }^{6}$ Aqui cabe uma importante e imprescindível ressalva. Ao falarmos da revelação e da fé estamos centrando nossa reflexão principalmente na religião cristã do Mundo Ocidental, pois há religiões naturais onde as revelações não ocorrem. $O$ fato de focarmos o pensamento religioso do mundo ocidental deriva da relativa hegemonia que o mesmo cultivou durante séculos, embora na contemporaneidade possamos falar de uma pluralidade de religiões pela valorização da cultura e identidade de cada povo que se reconhece e legitima enquanto tal.

${ }^{7}$ Por exemplo, na religião católica, Adão e Eva e o pecado original, onde o trabalho é visto como castigo e forma de expiação.

${ }^{8}$ A religião utiliza do recurso mítico para a construção dos exemplos que conformarão a ética e moral que orientará e servirá de parâmetro às ações humanas, influenciando nas escolhas entre alternativas dos indivíduos sociais. Daí dizermos que é uma visão religiosa-mítica ou míticoreligiosa.

${ }^{9}$ Jaeger expressa, de forma magistral, esse intercâmbio metabólico entre a natureza e o ser social, servindo de base para as considerações que foram tecidas em nosso parágrafo conclusivo. "(...) A vivacidade espontânea, a sutil mobilidade, a íntima liberdade [dos gregos] não têm as suas raízes no cultivo da subjetividade, como atualmente acontece; pertencem a sua natureza. E quando esse povo atinge a consciência de si próprio descobre, pelo caminho do espírito, as leis e normas objetivas cujo conhecimento dá ao pensamento e à ação uma segurança antes desconhecida. Do ponto de vista oriental, é impossível compreender como os artistas gregos conseguiram representar o corpo humano, livre e descontraído, fundado não na imitação de movimentos e atitudes individuais escolhidas ao acaso, mas sim na intuição das leis que governam a estrutura, o equilíbrio e o movimento do corpo. Do mesmo modo, a liberdade sofreada sem esforço, característica do espírito grego e desconhecida dos povos anteriores, baseia-se na consciência nítida de uma legalidade imanente das. Os gregos tiveram o senso inato do que significa 'natureza'. O conceito de natureza, 
elaborado por eles em primeira mão, tem indubitável origem na sua constituição espiritual. Muito antes de o espírito grego ter delineado essa idéia, eles já consideravam as coisas do mundo numa perspectiva tal que nenhuma delas Ihes aparecia como parte isolada do resto, mas sempre como um todo ordenado em conexão viva, na e pela qual tudo ganhava posição e sentido. Chamamos orgânica a esta concepção, porque nela todas as partes são consideradas membros de um todo. A tendência do espírito grego para a clara apreensão das leis do real, tendência patente em todas as esferas da vida - pensamento, linguagem, ação e todas as formas de arte -, radica-se nesta concepção do ser como estrutura natural, amadurecida, originária e orgânica." (JAEGER: 1995, p. 10 e 11)

RECEBIDO EM: 03.07.2012

APROVADO EM: 11.07.2012 